\title{
A coup for coupling
}

\author{
The 2010 Nobel Prize for Chemistry rewards a family of techniques for forging carbon-carbon bonds that \\ have already helped to create new organic materials.
}

If you want to win a Nobel Prize for Chemistry, find a good way to join together carbon atoms. That could be interpreted as the take-home message of last year's award to Richard Heck, Ei-ichi Negishi and Akira Suzuki. These names have, to even the cursory student of the chemical literature, taken on the depersonalized authority of Grignard, Diels and Alder in being no longer associated with real people, but simply with standard ways of making organic molecules.

Similar to those illustrious forebears, the 2010 chemistry laureates were rewarded for methods of creating the carbon backbones of complex molecules. Also belonging to this select group are Georg Wittig, whose 1979 prize recognized his method for linking the carbon of an aldehyde or ketone with that of a phosphonium ylide, and Yves Chauvin, Robert Grubbs and Richard Schrock, whose coordinated rearrangement of carboncarbon double bonds in olefin metathesis was awarded the 2005 prize ${ }^{1}$.

However, it is with the work of François Auguste Victor Grignard around the start of the twentieth century that the latest award shares most in common. For in both cases the coupling of carbon atoms is effected by a metal, which serves to activate carbon atoms into a reactive state. Grignard used magnesium, which insinuates itself into an alkyl-halogen bond to make an organometallic complex that reacts with ketones to produce alcohols. The Grignard reaction is wonderful in its way, but messy in practice: unselective, sensitive to moisture and unfriendly to acidic hydrogens in the substrate.

Heck, Negishi and Suzuki all came up with more versatile, gentler approaches based on the use of palladium. Heck, working at the Hercules Chemical Company in Delaware, discovered in the late 1960s that palladium will also insert into alkyl halides, where it can act as a matchmaker with olefins: the metal atom may at the same time coordinate to a carbon-carbon double bond, bringing the alkyl and olefin groups close enough to link up. The method also works for aryl halides, allowing, for example, the formation of styrene from ethylene and bromobenzene. A crucial step was to make the palladium act catalytically rather than, as with Grignard's magnesium,

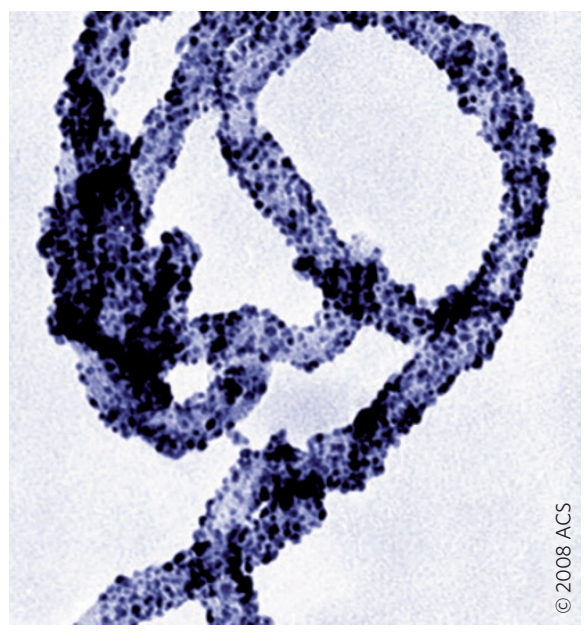

Carbon nanotubes covered with palladium nanoparticles are highly active catalysts for the Nobel-prize-winning cross-coupling reactions?

stoichiometrically, which made the cost amenable.

The Negishi and Suzuki 'cross-coupling' reactions (so-called because they unite two chemically distinct organic fragments) also start from the palladium-interpolated alkyl or aryl halide. Like the Heck reaction, the trick is to join this organic group to a carbon atom in another 'activated' species. For this species, Negishi, working at Purdue University in Indiana, found that organo-zinc, -aluminium and -zirconium compounds work well. Suzuki, at Hokkaido University in Japan, used organoboron compounds, which makes the process very mild and non-toxic.

Among the main uses of all these reactions have been the syntheses of complex natural products with large and intricate carbon backbones, such as the anti-cancer drug Taxol and the gargantuan, highly poisonous molecule palytoxin. Palladiumcatalysed cross-couplings have been used to make modified forms of the antibiotic vancomycin, the candidate antivirals dragmacidin $\mathrm{F}$ and hennoxazole $\mathrm{A}$, the anti-inflammatory drug naproxen and the herbicide prosulfuron. In several of these cases, the presence of sensitive functional groups elsewhere in the molecules makes a mild reagent essential.
But it's not just pharmaceutical chemists who have reason to celebrate this Nobel award. Even if organic materials chemistry doesn't generally deal with such complicated carbon frameworks, it may require gentle and selective ways of making carbon-carbon bonds. For example, the Heck reaction is used by the Dow Chemical Company to make the organosilicon monomer of its resin Cyclotene, used as a high-performance protective dielectric in microelectronics. Furthermore, palladiumcatalysed cross-coupling, especially the Suzuki reaction, offers a route to the synthesis of polyphenylenes, which act as conducting and light-emitting polymers in optoelectronic devices. This has proved a resoundingly popular method for making various oligomers used in blue- and green-light organic light-emitting diodes ${ }^{2-5}$.

The approach also works for functionalizing graphitic carbon, and has been used in this regard for carbon nanotubes ${ }^{6}$. What's more, inventive materials chemistry might offer new avenues for creating the catalysts themselves. Carbon nanotubes can act as a support for the palladium nanoparticles in Suzuki coupling ${ }^{7}$, and the tobacco mosaic virus was very recently reported as a template for synthesizing the nanoparticles themselves ${ }^{8}$. And even graphene, which garnered the 2010 physics Nobel for Andre Geim and Konstantin Novoselov, has been reported to be a promising support for a highactivity Suzuki catalyst ${ }^{9-11}$. When apparently disparate areas of science start coming together like that, it's a sure sign that the researchers involved have hit rich veins of creativity.

\footnotetext{
References

1. Nature Mater. 4, 877 (2005).

2. Wong. K-T. et al. Org. Lett. 4, 513-516 (2002).

3. Song, S. et al. Tetrahedron Lett. 49, 3582-3587 (2008).

4. Lopez, L. C., Strohriegl, P. \& Stübinger, T.

Macromol. Chem. Phys. 203, 1926-1930 (2002).

5. Lo, M. Y. \& Sellinger, A. Synlett 18, 3009-3012 (2006).

6. Cheng, F. \& Adronov, A. Chem. Mater. 18, 5389-5391 (2006).

7. Chen, X., Hou, Y., Wang, H., Cao, Y. \& He, J. J. Phys. Chem. C 112, 8172-8176 (2008).

8. Yang, C., Manocchi, A. K., Lee, B. \& Yi, H. J. Mater. Chem. 21, 187-194 (2011).

9. Scheuermann, G. M., Rumi, L., Steurer, P., Bannwarth, W. \& Mülhaupt, R. J. Am. Chem. Soc. 131, 8262-8270 (2009).

10. Li, N. et al. J. Nanosci. Nanotechnol. 10, 6748-6751 (2010). 11. Li, Y. et al. Nano Res. 3, 429-437 (2010).
} 